UC-700

Issued: April 1997

Application of Proposed Mutual Reciprocal Inspection Measurement Techniques to a Weapon Component

M. W. Johnson

C. M. Frankle

T. B. Gosnell*

${ }^{*}$ Lawrence Livermore National Laboratory

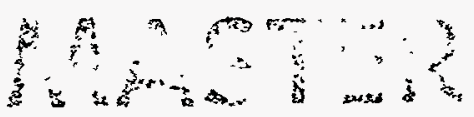




\section{DISCLAIMER}

Portions of this document may be illegible in electronic image products. Images are produced from the best available original document. 


\title{
APPLICATION OF PROPOSED MUTUAL RECIPROCAL INSPECTION MEASUREMENT TECHNIQUES TO A WEAPON COMPONENT
}

\author{
M. W. Johnson, C. M. Frankle, and T. B. Gosnell
}

\begin{abstract}
The shape-measurement technique proposed by Russian scientists for mutual reciprocal inspections (MRI) of plutonium from dismantled nuclear weapons has been applied to a US weapon component. Measurement procedures are described. Results of the measurements are "self-normalized" to remove any classified information and further renormalized to results of previous joint US/Russian measurements of an unclassified plutonium piece. Data are presented in tabular and graphical form, conforming to the method of presentation recommended by Russian experts during the previous measurements.
\end{abstract}

\section{INTRODUCTION}

In November 1996, United States and Russian scientists participated in joint measurements at the Lawrence Livermore National Laboratory (LLNL) to assess methods for determining the "shape" of plutonium pieces within storage containers. Shape measurements have been discussed by the two countries as part of a measurement suite for mutual reciprocal inspections (MRI) $)^{1.2}$ of plutonium removed from dismantled nuclear weapons, in accordance with the O'Leary-Mikhailov joint statement of March $1994^{3}$ that established the two countries' intentions of performing MRI. According to the joint document produced by Russian and US participants in the meeting, the objective of the LLNL measurements was

to conduct and discuss the two [shape] measurement techniques....and to accurately represent the measurements in graphical form.... It was not the objective of the November meeting to reach a decision on whether shape or both shape and size were necessary....

That document went on to state:

The technical experts agreed to conduct thorough and detailed internal analysis of the results of this report and, if appropriate, exchange the results of that analysis.... Having conducted the procedures...the sides will be able to compare the experimental data with actual signatures of the weapon components and will put the sides in a much better position to evaluate what measurements are necessary to confirm that $\mathrm{Pu}$ in a sealed container comes from a dismantled nuclear weapon. 
At the time of the LLNL measurements, no provisions existed yet for the exchange of classified/sensitive information connected with MRI. The LLNL measurements therefore had to be performed using unclassified pieces of plutonium. The question naturally arises as to how these measurements relate to "actual signatures of the weapon components," which, though amenable to measurement, could not be obtained during the LLNL studies. The present report is an attempt to shed light on this issue by exploring the signature of a particular US pit, while avoiding the presentation of classified data that would prevent the signature from being transmissible to Russian scientists.

\section{METHOD}

The experimental setup is shown in Figure 1. The pit was in a standard AL-R8 container that was placed on its side atop a rotary table in the LLNL Radiation Measurement Facility (RMF). Measurements were done atop an elevated platform to minimize the backscatter of neutrons from the walls of the RMF. The same site was used for the November 1996 measurements.

The detector used for these measurements was used by the US side in November 1996, and is derived from the well-known "SNAP" detector used in nuclear safeguards. 5 As in the November 1996 measurements, the detector was left in place while the AL-R8 was rotated on the rotary table about an axis perpendicular to that of the AL-R8 and passing through the center of the pit. Count rates were measured at 15 -degree increments.

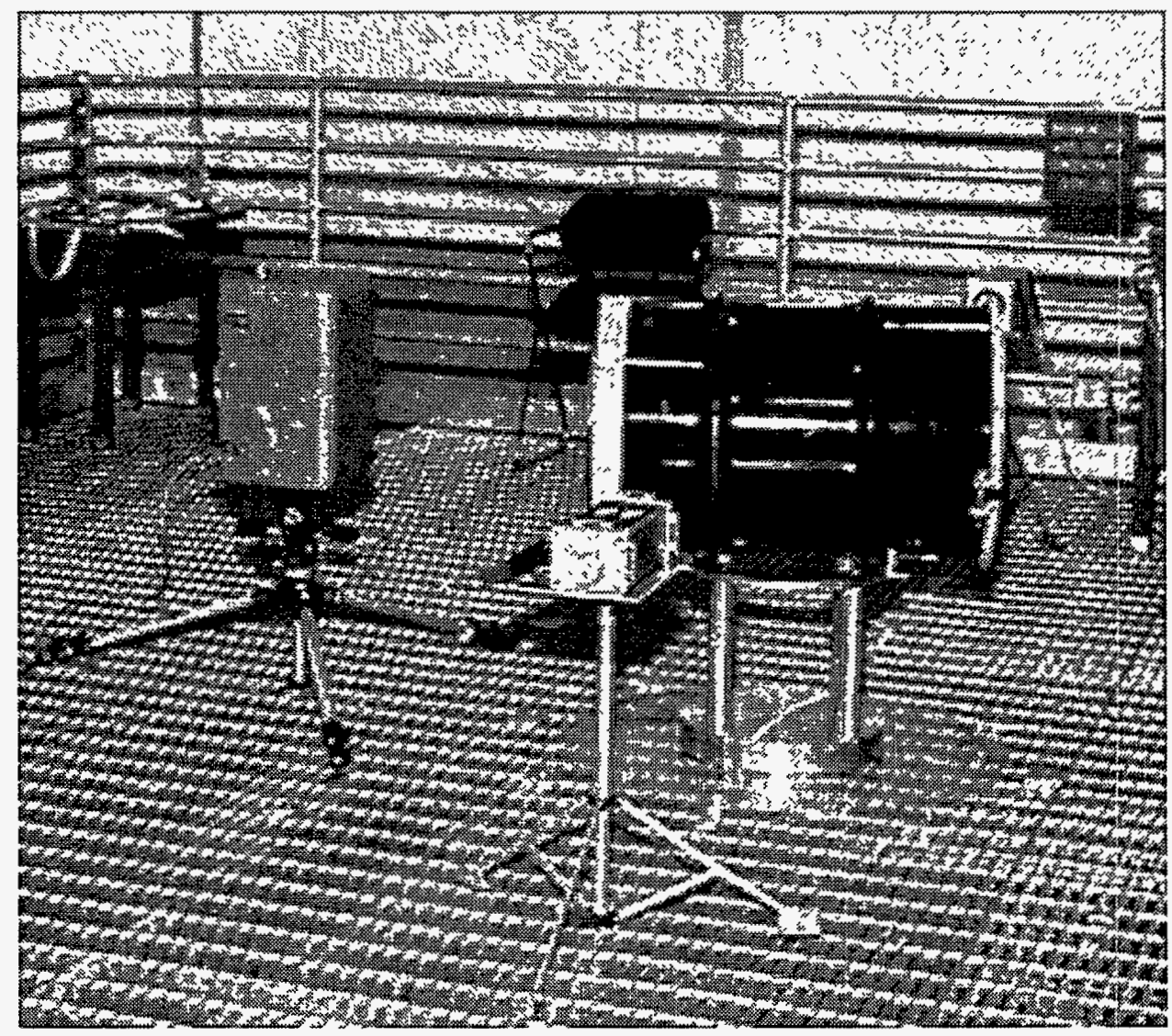

Fig. 1. Experimental setup at the RMF. The neutron detector is the instrument to the left of the $A L-R 8$. 
As the neutron count rates at a given location, with a detector of known efficiency, are classified Confidential/Restricted Data, it is impossible to give the rates here. Therefore the rates were "sanitized" through self-normalization, that is, division by the average of the rates obtained at all 24 measurement positions. This procedure was also used for self-normalization of the data obtained at the November 1996 LLNL experiments.

\section{RESULTS AND ANALYSIS}

The self-normalized rates are presented in tabular form in Table I and graphically in Figure 2. The point at 0 degrees represents the normalized rate obtained when the detector was facing the bottom of the AL-R 8 container, and the point at 180 degrees represents the normalized rate obtained when the detector faced the top of the container.

It is of interest to analyze these results using the procedures developed during the November experiments. At the suggestion of the Russian participants, data were obtained in November on the symmetrical "sphere" of $\mathrm{Pu}^{*}$ and self-normalized. The self-normalized data from the sphere (listed in Table II) were then divided into the self-normalized data on the pit to "renormalize" the data. The purpose is to account for container effects, which might affect the neutron leakage from the $\{\mathrm{Pu}+\mathrm{AL}-\mathrm{R} 8\}$ ensemble in unpredictable ways but might be presumed to be about the same, all else equal, for all spherically symmetrical plutonium objects. This procedure was also used in the generation of the results presented in Ref. 4.

Table I: Self-normalized data for the pit.

\begin{tabular}{|c|c|}
\hline $\begin{array}{c}\text { Angle } \\
\text { (degrees) }\end{array}$ & $\begin{array}{c}\text { Relative } \\
\text { count rate }\end{array}$ \\
\hline 0 & 0.969 \\
\hline 15 & 0.749 \\
\hline 30 & 0.719 \\
\hline 45 & 0.844 \\
\hline 60 & 0.958 \\
\hline 75 & 1.022 \\
\hline 90 & 0.967 \\
\hline 105 & 1.008 \\
\hline 120 & 0.926 \\
\hline 135 & 0.905 \\
\hline 150 & 1.064 \\
\hline 165 & 1.188 \\
\hline
\end{tabular}

\begin{tabular}{|c|c|}
\hline $\begin{array}{c}\text { Angle } \\
\text { (degrees) }\end{array}$ & $\begin{array}{c}\text { Relative } \\
\text { count rate }\end{array}$ \\
\hline 180 & 1.193 \\
\hline 195 & 1.262 \\
\hline 210 & 1.163 \\
\hline 225 & 1.065 \\
\hline 240 & 1.009 \\
\hline 255 & 1.119 \\
\hline 270 & 1.109 \\
\hline 285 & 1.154 \\
\hline 300 & 1.118 \\
\hline 315 & 0.909 \\
\hline 330 & 0.733 \\
\hline 345 & 0.847 \\
\hline
\end{tabular}

\footnotetext{
- The 'sphere' was not completely spherically symmetric, but had a small indentation on one side; for the normalization measurements, the sphere was positioned so that this indentation was aligned along the axis of rotation, so that the distribution of plutonium, and therefore presumably of neutrons escaping the plutonium, was at least cylindrically symmetric about this axis.
} 


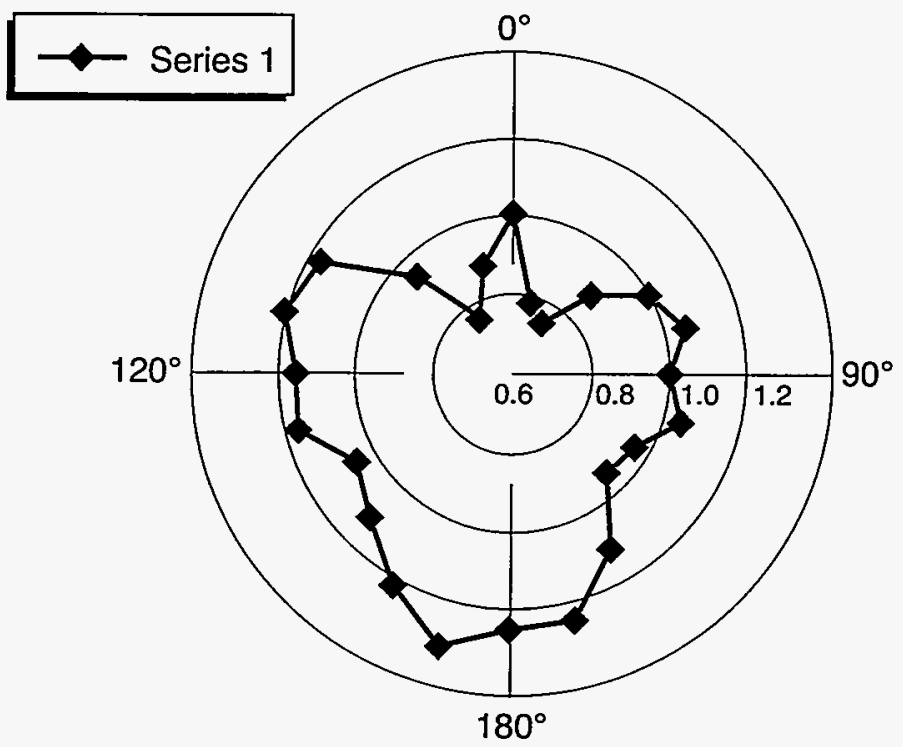

Fig. 2. Rose plot of self-normalized (relative) neutron count rates from the weapon component.

Table II: Self-normalized data for the reference Pu "sphere," obtained during the November 1996 measurements.

\begin{tabular}{|c|c|}
\hline $\begin{array}{c}\text { Angle } \\
\text { (degrees) }\end{array}$ & $\begin{array}{c}\text { Relative } \\
\text { count rate }\end{array}$ \\
\hline 0 & 1.148 \\
\hline 15 & 1.089 \\
\hline 30 & 0.818 \\
\hline 45 & 0.837 \\
\hline 60 & 0.951 \\
\hline 75 & 1.064 \\
\hline 90 & 1.047 \\
\hline 105 & 1.040 \\
\hline 120 & 0.920 \\
\hline 135 & 0.893 \\
\hline 150 & 1.004 \\
\hline 165 & 1.184 \\
\hline
\end{tabular}

\begin{tabular}{|c|c|}
\hline $\begin{array}{c}\text { Angle } \\
\text { (degrees) }\end{array}$ & $\begin{array}{c}\text { Relative } \\
\text { count rate }\end{array}$ \\
\hline 180 & 1.152 \\
\hline 195 & 1.123 \\
\hline 210 & 0.920 \\
\hline 225 & 0.951 \\
\hline 240 & 0.970 \\
\hline 255 & 1.131 \\
\hline 270 & 1.054 \\
\hline 285 & 1.025 \\
\hline 300 & 0.872 \\
\hline 315 & 0.830 \\
\hline 330 & 0.869 \\
\hline 345 & 1.110 \\
\hline
\end{tabular}


Results of the renormalization are presented in tabular form in Table III and graphical form in Fig. 3. The same format is used in Fig. 3 as in the plots in Ref. 4, i.e., the R-axis values range from 0.6 to 1.2 regardless of the actual values of the renormalized data. This presentation format was chosen to expedite comparison of the present results with those from the November 1996 measurements, an example of which is included here as Fig. 4.

Table III: Renormalized data for the pit.

\begin{tabular}{|c|c|}
\hline $\begin{array}{c}\text { Angle } \\
\text { (degrees) }\end{array}$ & $\begin{array}{c}\text { Relative } \\
\text { count rate }\end{array}$ \\
\hline 0 & 0.845 \\
\hline 15 & 0.688 \\
\hline 30 & 0.878 \\
\hline 45 & 1.009 \\
\hline 60 & 1.007 \\
\hline 75 & 0.961 \\
\hline 90 & 0.924 \\
\hline 105 & 0.969 \\
\hline 120 & 1.007 \\
\hline 135 & 1.014 \\
\hline 150 & 1.060 \\
\hline 165 & 1.004 \\
\hline
\end{tabular}

\begin{tabular}{|c|c|}
\hline $\begin{array}{c}\text { Angle } \\
\text { (degrees) }\end{array}$ & $\begin{array}{c}\text { Relative } \\
\text { count rate }\end{array}$ \\
\hline 180 & 1.036 \\
\hline 195 & 1.124 \\
\hline 210 & 1.264 \\
\hline 225 & 1.120 \\
\hline 240 & 1.040 \\
\hline 255 & 0.990 \\
\hline 270 & 1.052 \\
\hline 285 & 1.125 \\
\hline 300 & 1.282 \\
\hline 315 & 1.095 \\
\hline 330 & 0.843 \\
\hline 345 & 0.763 \\
\hline
\end{tabular}

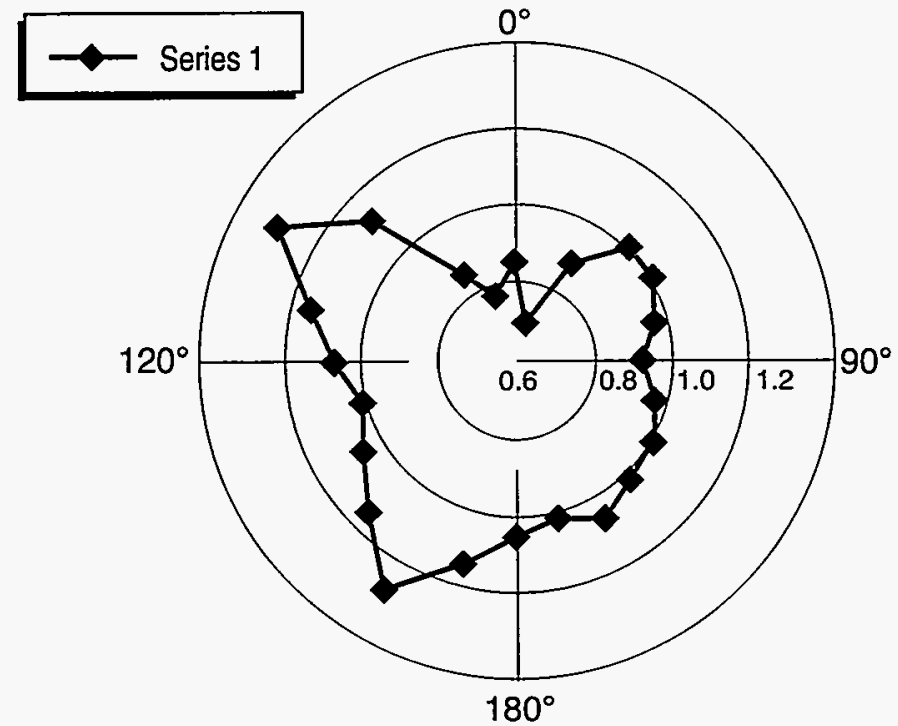

Fig. 3. Rose plot of the self-normalized count rates after renormalization to the plutonium sphere data obtained during the November 1996 LLNL measurements. 


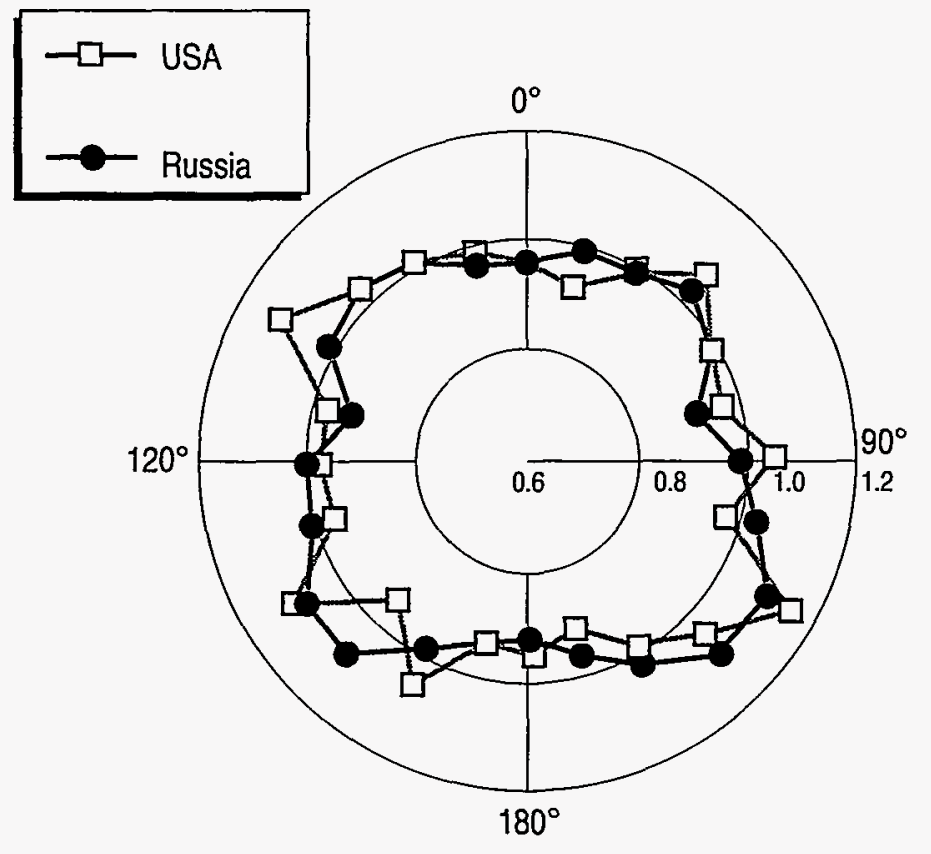

Fig. 4. Rose plot of self-normalized neutron count rates from the plutonium oxide sample used in the November 1996 LLNL measurements (from Ref. 4).

\section{ACKNOWLEDGMENTS}

We acknowledge advice from A. J. Bieniawski, DOE NN-42, and LTC G. D. Lunsford, DoD OSTP, who suggested the value of compiling this report. The assistance of B. Kitt and the staff of the RMF in performing the measurements is also appreciated.

\section{REFERENCES}

1. C. Mark Percival and Timothy H. Ingle, "Overview of Joint Statement on Reciprocal Inspection of Fissile Materials Removed from Nuclear Weapons," INMM Journal of Nuclear Materials Management, July 1994, Vol. XXII, pp. 19-21.

2. M. W. Johnson and T. B. Gosnell, "Progress Toward Mutual Reciprocal Inspections of Fissile Materials from Dismantled Nuclear Weapons," 36th Annual Meeting of the Institute for Nuclear Materials Management, Palm Desert, CA, July 9-12, 1995 (Los Alamos National Laboratory report LA-UR-95-2335).

3. Department of Energy, "Joint Statement on Inspection of Facilities Containing Fissile Materials Removed from Nuclear Weapons," released to press 16 March 1994.

4. Report of the Joint Measurements and Discussions Conducted at the Lawrence Livermore National Laboratory, November 1996. Note: This report, intended for members of the joint US/Russian measurement team, is not available through regular government distribution agencies.

5. J. Sprinkle, "Total Neutron Counting Instruments and Applications," in D. Reilly, N. Ensslin, H. Smith, Jr., and S. Kreiner, "Passive Nondestructive Assay of Nuclear Materials," Nuclear Regulatory Commission NUREG/CR-5550. 